\title{
DNA copy number alterations in central primitive neuroectodermal tumors and tumors of the pineal region: an international individual patient data meta-analysis
}

von Bueren, André O ; Gerss, Joachim ; Hagel, Christian ; Cai, Haoyang ; Remke, Marc ; Hasselblatt, Martin ; Feuerstein, Burt G ; Pernet, Sarah ; Delattre, Olivier ; Korshunov, Andrey ; Rutkowski, Stefan ; Pfister, Stefan M ; Baudis, Michael

\begin{abstract}
Little is known about frequency, association with clinical characteristics, and prognostic impact of DNA copy number alterations (CNA) on survival in central primitive neuroectodermal tumors (CNSPNET) and tumors of the pineal region. Searches of MEDLINE, Pubmed, and EMBASE-after the original description of comparative genomic hybridization in 1992 and July 2010-identified 15 case series of patients with CNS-PNET and tumors of the pineal region whose tumors were investigated for genomewide CNA. One additional case study was identified from contact with experts. Individual patient data were extracted from publications or obtained from investigators, and CNAs were converted to a digitized format suitable for data mining and subgroup identification. Summary profiles for genomic imbalances were generated from case-specific data. Overall survival (OS) was estimated using the Kaplan-Meier method, and by univariable and multivariable Cox regression models. In their overall CNA profiles, low grade tumors of the pineal region clearly diverged from CNS-PNET and pineoblastoma. At a median follow-up of 89 months, 7-year OS rates of CNS-PNET, pineoblastoma, and low grade tumors of the pineal region were $22.9 \pm 6,0 \pm 0$, and $87.5 \pm 12 \%$, respectively. Multivariable analysis revealed that histology (CNS-PNET), age ( 2.5 years), and possibly recurrent CNAs were associated with unfavorable OS. DNA copy number profiling suggests a close relationship between CNS-PNET and pineoblastoma. Low grade tumors of the pineal region differed from CNS-PNET and pineoblastoma. Due to their high biological and clinical variability, a coordinated prospective validation in future studies is necessary to establish robust risk factors.
\end{abstract}

DOI: https://doi.org/10.1007/s11060-012-0911-7

Posted at the Zurich Open Repository and Archive, University of Zurich

ZORA URL: https://doi.org/10.5167/uzh-64879

Journal Article

Accepted Version

Originally published at:

von Bueren, André O; Gerss, Joachim; Hagel, Christian; Cai, Haoyang; Remke, Marc; Hasselblatt, Martin; Feuerstein, Burt G; Pernet, Sarah; Delattre, Olivier; Korshunov, Andrey; Rutkowski, Stefan; Pfister, Stefan M; Baudis, Michael (2012). DNA copy number alterations in central primitive neuroectodermal tumors and tumors of the pineal region: an international individual patient data meta-analysis. Journal of Neuro-Oncology, 109(2):415-423.

DOI: https://doi.org/10.1007/s11060-012-0911-7 


\title{
DNA copy number alterations in central primitive
}

\author{
neuroectodermal tumors and tumors of the pineal
}

region: an international individual patient data meta-

\section{analysis}

André O. von Bueren ${ }^{1,4}$, Joachim Gerss ${ }^{2}$, Christian Hagel $^{3}$, Haoyang $\mathrm{Cai}^{4}$, Marc

Remke $^{5}$, Martin Hasselblatt ${ }^{6}$, Burt G. Feuerstein ${ }^{7}$, Sarah Pernet ${ }^{8}$, Olivier Delattre ${ }^{8}$, Andrey Korshunov ${ }^{9}$, Stefan Rutkowski ${ }^{1}$, Stefan M. Pfister ${ }^{5}$, and Michael Baudis ${ }^{4}$

${ }^{1}$ Department of Pediatric Hematology and Oncology, University Medical Center Hamburg-Eppendorf, Hamburg, Germany

${ }^{2}$ Institute of Biostatistics and Clinical Research, University of Muenster, Germany

${ }^{3}$ Institute of Neuropathology, University Medical Center Hamburg-Eppendorf, Hamburg, Germany

${ }^{4}$ Institute of Molecular Life Sciences, University of Zurich, Zurich, Switzerland

${ }^{5}$ Division Molecular Genetics, German Cancer Research Center, Heidelberg, and

Department of Pediatric Hematology and Oncology, Heidelberg University Hospital,

Germany

${ }^{6}$ Institute of Neuropathology, University of Muenster, Germany

${ }^{7}$ Department of Neurology, Barrow Neurologic Institute, University of Arizona

College of Medicine, Phoenix, Arizona, USA

${ }^{8}$ Institut Curie, Unité de génétique somatique, Paris, France

${ }^{9}$ Department of Neuropathology, University of Heidelberg, Heidelberg, Germany 
Correspondence to: André O. von Bueren, M.D., Ph.D.

Department of Pediatric Hematology and Oncology

University Medical Center Hamburg-Eppendorf

Martinistrasse 52, D-20246 Hamburg, Germany

Phone: ++49 40-7410-55842; Fax:++49 40-7410-58300

E-mail: a.von-bueren@uke.de

Keywords: Chromosomal imbalances Prognostic markers Comparative genomic hybridization Brain tumor 


\section{Abstract}

Little is known about frequency, association with clinical characteristics, and prognostic impact of DNA copy number alterations (CNA) on survival in central primitive neuroectodermal tumors (CNS-PNET) and tumors of the pineal region. Searches of MEDLINE, Pubmed, and EMBASE - after the original description of comparative genomic hybridization and July 2010 - identified 15 case series of patients with CNS-PNET and tumors of the pineal region whose tumors were investigated for genome-wide CNA. One additional case study was identified from contact with experts. Individual patient data were extracted from publications or obtained from investigators, and CNAs were converted to a digitized format suitable for data mining and subgroup identification. Summary profiles for genomic imbalances were generated from case specific data. Overall survival (OS) was estimated using Kaplan-Meier method, by univariable, and multivariable Cox regression models. In their overall CNA profiles, low grade tumors of the pineal region clearly diverged from CNS-PNET and pineoblastoma. At a median follow-up of 89 months, 7-year OS rates of CNS-PNET, pineoblastoma, and low grade tumors of the pineal region were $22.9 \% \pm 6 \%, 0 \% \pm 0 \%$, and $87.5 \% \pm 12 \%$, respectively. Multivariable analysis revealed that histology (CNS-PNET), age ( $\leq 2.5$ years), and possibly recurrent CNAs were associated with unfavorable OS. DNA copy number profiling suggests a close relation between CNS-PNET and pineoblastoma. Low grade tumors of the pineal region differed from CNS-PNET and pineoblastoma. Due to their high biological and clinical variability, a coordinated prospective validation in future studies is necessary to establish robust risk factors. 


\section{Introduction}

Central nervous system primitive neuroectodermal tumors (CNS-PNET) are a heterogeneous group of WHO grade IV lesions (Supplementary Table 1). They comprise $3-7 \%$ of brain tumors in children and young adults [1-2] and are associated with a dismal prognosis [3-4]. Histologically, these highly proliferative lesions are currently divided into CNS-PNET or supratentorial PNET, respectively (synonym PNET not otherwise specified, PNET NOS), CNS neuroblastoma, CNS ganglioneuroblastoma, medulloepithelioma, and ependymoblastoma [5]. CNS-PNET and medulloblastoma share a similar histology and are often solely distinguishable by their supratentorial versus infratentorial location. Further, pineoblastoma, a WHO grade IV tumor of the pineal gland [5], is filed in some studies as CNS-PNET although pineoblastoma forms a group of neoplasms of the pineal region together with pineocytoma, pineal parenchymal tumor of intermediate differentiation, and papillary tumor of the pineal region [5]. The classification of malignancies within the group of embryonal tumors has changed considerably in the last four editions of the WHO classification of tumors of the CNS (Supplementary Table 1). Tumor classification systems are increasingly complemented by molecular genetic profiling data, especially in hematologic neoplasias [6]. However, for the various subtypes of CNSPNET such data is still scarce and large series are missing. Profiling of regional copy number abnormalities (CNA) by genomic hybridization techniques is a robust methodology for whole genome data analysis. Principle techniques include the different variants of chromosomal and array based comparative genomic hybridization (cCGH/aCGH; [7-10]) and single-color oligonucleotide array technologies (e.g. genomic single nucleotide polymorphism (SNP) arrays). 
In contrast to data from gene expression measurements, $\mathrm{CGH}$ data is easily adaptable across multiple datasets to perform a meta-analysis. Methods to assess genomic CNAs are standardized and reproducible as demonstrated in previous reports (e.g. [11-12]). Some earlier reviews have reported on specific types of aberrations or were focused on the descriptive analysis of certain classes of malignancies [13-14].

Due to the low incidence of CNS-PNET and pineoblastoma, only a few CGH studies have been reported in these tumors [2, 15-17]. So far, results have suggested that CNS-PNET are genetically heterogeneous with frequent and diverse CNAs and that CNA patterns are distinct from those observed in medulloblastoma [2, 15-17]. For the present study, we performed an individual patient data (IPD) meta-analysis - a specific method of systematic review [18] offering advantages for meta-analysis [1920] - of genomic imbalances in CNS-PNET and tumors of the pineal region. The collected data is made available through the "Progenetix" molecular-cytogenetic database (www.progenetix.org: [14, 21-22]). 


\section{Methods}

\section{Search strategy, and selection criteria}

We did a modification of the Cochrane Highly Sensitive Search Strategy for prognostic studies [20] combined with predefined search terms in MEDLINE, Pubmed, and EMBASE without language restriction [23-24]. The process of the study retrieval, in- and exclusion of studies/patients is displayed in the flow chart (Fig. 1) according to the PRISMA (Preferred Reporting Items for Systematic Reviews and Meta-Analyses) statement. The search was limited to articles published after the original description of CGH [7] until July 2010. Key words were: "medullo()blastoma(s)", "primitive neuroectodermal tumo(u)r(s)", "neuroectodermal tumo(u)r(s) primitive" "pnet(s)", "medullo(-)epithelioma(s)", “ependymoblastoma(s)", "ganglioneuroblastoma(s)", "pinealoma”, "pineocytoma(s)", “pineoblastoma(s)", "pineal tumo(u)r(s)", "pineal parenchymal tumo(u)r(s)", "mixed transitional pineal tumo(u)r(s)", "mixed transitional pineal tumo(u)r(s)", "atypical teratoid rhabdoid tumo(u)r(s)", "rhabdoid tumo(u)r(s)", "AT(/)RT" and "rhabdoid", "supratentorial neoplasm(s)" or "neuroblastoma(s)" and "central nervous system neoplasm(s)"; and "cgh" or "comparative genomic hybridization" or "snp" or "single nucleotide polymorphism" or "genomic array(s)" or "copy number" or "dna microarray(s)" or "amplification". Additionally to the search queries, we followed references from the selected articles and assessed each abstract. Minimal requirements for inclusion of a patient to the study were the availability of case specific genomic copy number data with whole genome coverage, the unambiguous diagnostic classification of CNS-PNET/tumor of the pineal region, and matching available or inferred locus information. 


\section{Clinical and CNA data collection, data extraction, quality assessment, conversion of CNA data, and data synthesis}

For CGH results specified in cytogenetic annotation formats, data was standardized to ISCN 1995 (International System for Human Cytogenetic Nomenclature (1995)) "rev ish" format based on an 862 bands karyotype and checked for semantically correct annotation using dedicated software. For genomic array data without annotated gain/loss information, clone specific data files were segmented using Progenetix website tools. Normalized data was converted to Golden Path mapped copy number status information by software implemented in the Perl scripting language [14]. In a first step, clinical and genomic data were extracted from publications by two reviewers (AOVB and MB). Subsequently, the original data, in particular in case of incomplete data (genomic and clinical data), for each participant was obtained and updated directly from the researcher responsible for each included study [25]. To prevent duplicate inclusions, authors were asked to indicate whether a patient had been analyzed within different studies. In addition, copy number profiles were clustered for similarity and reviewed for the occurrence of profile pairs, in order to avoid duplicate cases due to republished data. Data of 3 unpublished CNS-PNET patients were provided by two authors (SP and OD). Generally, two approaches to perform IPD meta-analyses are used. First, IPD meta-analyses can be performed directly, as if all data belong to a single trial/study, termed the "one-stage" approach [26]. Second, a "two-stage" approach can be also used. Each trial/study is analyzed separately using its raw data before the summary results from each trial/study are pooled and analyzed using conventional meta-analyses techniques [26]. Due to the small patient numbers of each individual case series the "one-stage" approach was used here. 


\section{Exploratory data mining and statistical analysis}

For the evaluation of regional copy number changes, non-overlapping genomic segments were generated based on the complete CNA data from all cases. For each of these intervals, case specific involvement was evaluated and gain/loss frequencies determined. For visualization and ordering of case specific CNA data, data matrices were produced containing imbalance status (gain, or loss) mapped to a variety of genomic intervals (from chromosomal arm level down to $1 \mathrm{Mb}$ ). Cases were ordered by hierarchical clustering of gain/loss matrices (unsupervised, complete linkage), and the derived case order was used for re-plotting of the original CNA annotations. A relatively resolution-independent surrogate marker of genomic instability, CNA complexity, was determined for each case by evaluating the occurrence of gain and loss events per chromosome arm, with a maximum score of 2 per arm (i.e. occurrence of one or more of each gain and loss; modified from [27]).

To evaluate imbalance distribution in relation to diagnostic assignment, for each of the entities in our dataset gain/loss frequencies were calculated mapped to genomic intervals on a $5 \mathrm{Mb}$ level. Copy number profiles were compared by generating a heatmap of gain/loss distributions.

Cases with clinical follow-up were evaluated with respect to correlation of clinical factors and regional CNA status to OS. OS was defined as date of diagnosis to death of any cause or to the date of last visit. Cut-off values of age and CNA complexity were determined by recursive partitioning [28]. Univariable and multivariable survival analyses were performed. OS was estimated by the Kaplan-Meier method, and the log-rank test was used for comparisons of survival in different groups [29]. Univariable analyses to investigate the effect of age (continuous), and CNA 
complexity (continuous) on OS was done with univariable Cox regression analysis. Multivariable analyses were performed using Cox's proportional hazards model. All statistical analyses are intended to be rather exploratory than confirmatory. P-values are considered statistically significant in case $p<0.05$. No adjustment for multiple testing was carried out. Statistical analyses were performed using SAS (Version 9.2 for Windows, SAS Institute Inc., Cary, NC, USA), and PASW Statistics 18 for Windows (SPSS Inc., Chicago, IL, USA). 


\section{Results}

Figure 1 illustrates the process of evaluating articles for inclusion in the IPD metaanalysis. We identified 1220 papers by the search terms. The number of papers was reduced to 840 after removing of duplicates (by titles and abstracts). Title and abstract review resulted in the exclusion of 710 papers. Three case specific data (one case series) were provided by two authors. We reviewed 131 papers in full, from which 15 studies, and one unpublished case series $(n=3)$, met inclusion criteria for this study (Supplementary Figure 1).

\section{Study characteristics and quality assessment}

The 16 studies included here comprised 107 patients in total, after exclusion of 4 cases with ambiguous CNA profiles. From 61 patients information about OS was available (clinical characteristics are shown in Table 1). Of those, 38 patients were profiled using aCGH and 23 patients using cCGH. The median follow-up time for survivors was 75 months, and the median follow-up time across all patients was 89 months. Fifteen children were aged $\leq 2.5$ years, 46 patients were aged $>2.5$ years. The cohort compromised all tumor entities classified as CNS-PNET in the current WHO classification when taking into account the update of earlier WHO classification in which some of these tumors were partly classified as different subgroups of embryonal tumors $[5,30](n=46)$, and tumors of the pineal region $(n=15)$ which included pineocytoma $(n=4)$, pineal parenchymal tumor of intermediate differentiation $(n=3)$, papillary tumor of the pineal region $(n=5)$, and pineoblastoma $(n=3)$. Mean CNA complexity was 9.4 (range, 0.00-30.00). For the purpose of statistical analysis, CNS-PNET were considered as one group and tumors of the pineal region were considered as another group. 


\section{Overall genomic imbalance patterns in central nervous system primitive neuroectotermal tumors and tumors of the pineal region}

In order to evaluate the overall patterns of genomic imbalances in bona fide CNSPNET and tumors of the pineal region, we visualized the case-specific CNAs of all tumors clustered for their overall imbalance similarities (Fig. 1 a). In CNS-PNET $(n=88)$, frequent gains of chromosomes 1q4 $(n=31[35 \%]), 2 p 2(n=27[31 \%])$, and $7 \mathrm{q} 3(\mathrm{n}=16[18 \%])$ as well as losses involving chromosome $13 \mathrm{q} 2(\mathrm{n}=21[24 \%])$, and $6 q(n=18[20 \%])$ could be observed among other less frequent changes (Fig. 1 b). In contrast, low grade tumors of the pineal region were characterized by gains of chromosomes 4q2 $(n=6[46 \%])$, and $12(n=5[38 \%])$ as well as losses of chromosomes $10(n=4[31 \%])$, and $22(n=5[38 \%])$. Interestingly, pineoblastoma $(n=6)$ displayed a pattern of genomic imbalances unrelated to the changes observed in the group of low grade tumors of the pineal region. Supplementary Figures 2-4 illustrate gains and losses of the different disease entities.

We observed frequent gains involving chromosome 2 and losses involving chromosome 6 in ependymoblastoma as well as in medulloepithelioma (Supplementary Fig. 3b, 3c). Losses of chromosome 6 and 13 were typical for ependymoblastoma.

Embryonal tumor with abundant neuropil and true rosettes (ETANTR) was first described by Eberhart et al. [31], but is so far not listed as a distinct tumor entity in the 2007 WHO classification [5] and represents a CNS-PNET with "ependymoblastic" rosettes [32]. Recently, Korshunov and colleagues demonstrated in a series of 21 ependymoblastoma and 20 ETANTR that 95\% of ETANTRs and $90 \%$ of ependymoblastoma have the unique focal amplification at $19 q 13.42$ [33]. 
Therefore, the term embryonal tumor with multilayered rosettes (ETMR) has been suggested for ependymoblastoma and ETANTR, a new entity with multilayered rosettes for which amplification at 19q13.42 represents a rather sensitive and specific marker [32].

In our cohort we identified 9 tumors with such an amplification (one ETANTR reported by Pfister et al. [33]; all other tumors reported by Li et al. [2]). As described previously by Li et al. [2], cases with such an amplification predominantly (8/9) also displayed gains of the whole or the major part of chromosome 2. For some additional cases with gain of chromosome 2 identified by $\mathrm{cCGH}$, no high resolution data was available. Therefore, we may not role out an additional amplification at 19q13.42 in these cases.

\section{Univariable and multivariable survival analysis of clinical factors and CNA complexity}

To assess which parameters contribute to prognosis, we evaluated each clinical variable by univariable Kaplan-Meier analysis. Tested variables were: Gender, age, histology, (CNS-PNET versus tumors of the pineal region), metastatic stage (no metastases versus metastases), extent of postoperative residual disease (complete/gross total resection versus residual disease $\geq 1.5 \mathrm{~cm}^{2}$ ), radiotherapy (no radiotherapy/local radiotherapy versus cranio-spinal radiotherapy), chemotherapy (no chemotherapy versus chemotherapy), CNA complexity ( $<11$ versus $\geq 11$ as defined by recursive partitioning), tumor sample source (primary tumor versus relapse), and technique (aCGH versus cCGH). Supplementary Table 2 illustrates the factors (histology, CNA complexity, and age) showing differences as assessed by univariable analysis. Patients with tumors of the pineal region had a more favorable OS when compared to patients with CNS-PNET (7-year OS: $64.7 \% \pm 15 \%$ versus $22.9 \% \pm 6 \%$, 
$\mathrm{p}=0.007)$. Of note, all three patients with a pineoblastoma and available follow-up were dead 33 months after diagnosis, whereas all other patients with low grade tumors of the pineal region had excellent outcome (7-year OS: $87.5 \% \pm 12 \%$ ). Patients aged $\leq 2.5$ years had unfavorable OS when compared to patients aged $>2.5$ years ( 7 -year OS: $0 \% \pm 0 \%$ versus $41.3 \% \pm 8 \%, \mathrm{p}=0.001)$. OS rates were similar in CNS-PNET patients with and without the amplification at 19q13.42. Univariable cox regression analysis confirmed that increasing age (continuous variable) is denoting a more favorable OS (hazard ratio, 0.967 [per year]; 95\% confidence interval, 0.939-0.996; P $=0.0282$ ) and increasing CNA complexity (continuous variable) a less favorable OS (hazard ratio, 1.063 [per unit]; 95\% confidence interval, 1.012-1.117; $\mathrm{P}=0.0153$ ). Multivariable analysis of clinical factors and CNA complexity revealed that histology (tumors of the pineal region), age (older than 2.5 years) and CNA complexity $<11$ are favorable prognostic factors (Table 2).

\section{Multivariable survival analysis of chromosomal aberrations, CNA complexity, and clinical factors}

To identify which of the chromosomal aberrations might have an impact on OS, multivariable survival analyses were applied to all 61 patients incorporating the significant clinical factors (histology, and age), CNA complexity, as well as 75 different chromosomal gains and 75 different chromosomal losses in a stepwise approach, respectively. These analyses finally revealed that young age ( $\leq 2.5$ years), histology (CNS-PNET), and recurrent gains of $3 \mathrm{p} 1$ $(\mathrm{n}=3 ; 5 \%), 13 \mathrm{q} 1(\mathrm{n}=5 ; 8.2 \%)$, and $15 \mathrm{q} 2(\mathrm{n}=8 ; 13.1 \%)$ are associated with an increased risk for unfavorable OS (Table 3). 


\section{Discussion}

Over the last years, whole genome/transcriptome molecular analysis has led to the identification of divergent biological characteristics in what were considered single cancer types. In the field of pediatric neuro-oncology, medulloblastoma are now considered as a group of biologically differing entities consisting of at least 4 molecular subgroups, loosely connected through their topography (cerebellum) and partially overlapping histological appearance [34-42].

Molecular studies in rare tumor entities are severely limited due to the low number of cases included in single series, as well as conceptual and technical heterogeneity of the studies. To our knowledge, our study is the first IPD meta-analysis assessing the genomic and clinical features in CNS-PNET and tumors of the pineal region and their impact on OS. In this study, we show that CNS-PNET and pineoblastoma are divergent in their CNA profiles when compared with low grade tumors of the pineal region. For the cases analyzed here, recurring CNA observed only in low grade tumors of the pineal region were e.g. gains on $4 q 2,9 p, 12 p$, and $8 q 2$ as well as deletions of chromosome 10. In contrast, recurring CNA only found in pineoblastoma were deletions on 4q, chromosome 9, and 1p3. Based on our results, CGH analysis might be of help - in addition to neuroradiological and histopathological evaluation to differentiate between CNS-PNET, pineoblastoma, and lower WHO grade tumors of the pineal region. While detection of the listed aberrations may be indicative for assignment to one of the diagnostic groups, development of a CNA-based classifier will ideally require larger numbers of genome profiles.

We found evidence that younger age at time of diagnosis is a negative prognostic factor for OS, confirming several previous studies reporting on poor outcome of 
young children with CNS-PNET/pineoblastoma [3, 43]. Timmermann and colleagues report on OS and progression-free survival rates after 3 years of $17.2 \%$ and $14.9 \%$, respectively [3]. Administration of radiotherapy was the only significant prognostic marker (15 out of 29 patients were not irradiated) in this study [3] suggesting that omitting the radiotherapy in young children - with the goal to reduce neurologic sequelae - might at least explain partly the extremely poor outcome of young children with CNS-PNET/pineoblastoma.

In our cohorts, CNS-PNET and pineoblastoma shared an unfavorable prognosis. Small numbers of pineoblastoma (3 out of 61 patients) may limit the comparison of those two tumor entities. Based on the literature, there is some evidence that patients with pineoblastoma may do better than patients with CNS-PNET [44-45]. Patients with low grade tumors of the pineal region had a favorable outcome (7-year OS: $87.5 \% \pm 12 \%$ ) confirming that those tumor entities need a less aggressive treatment than CNS-PNET/pineoblastoma.

CNS-PNET and tumors of the pineal region share a complex karyotype with frequent CNAs [46]. In our series of 107 patients, low grade tumors of the pineal region showed relative frequently absence of CNAs (4/13), less frequently in pineoblastoma (1/6), and CNS-PNET (2/88).

Recently, a new entity of CNS-PNET termed ETMR has been suggested for a subgroup of CNS-PNET (ependymoblastoma and ETANTR) for which amplification at $19 \mathrm{q} 13.42$ represents a rather sensitive and specific marker [32]. Korshunov et al. [33] identified in the great majority of ependymoblastoma and ETANTR the focal amplification at $19 \mathrm{q} 13.42$ whereas such an amplification was not observed in a large

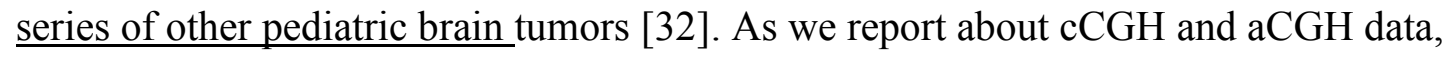
the frequency of tumors with amplification at 19q13.42 (Supplementary Fig. 6) 
should be interpreted with caution as detection of the amplification at 19q13.42 might be missed when tumors are profiled by conventional cCGH which has a spatial resolution limited of several megabases. Patients with 19q13.42 amplified tumors had a relatively poor OS (6/7 patients with available follow-up died of disease). Of note, $\underline{\text { the analysis of the prognostic impact of the amplification at } 19 \mathrm{q} 13.42 \text { is limited in our }}$ $\underline{\text { cohort, because - as mentioned above - this amplification might be missed in tumors }}$ analyzed with cCGH.

Our results provide evidence that high CNA complexity is an unfavorable prognostic marker in our cohort. Because of high frequencies of genomic imbalances as well as heterogeneous patterns and frequencies of CNAs, CNA complexity appears to be a good measure for overall genomic instability which may reflect aggressiveness of a certain tumor. In light of this, specific recurrent genomic imbalances which have been identified as CNAs with potential impact on OS in our analyses (e.g. in the 61 patients: gain of $\operatorname{seg} 3 \mathrm{p} 1(\mathrm{n}=3), \operatorname{seg} 13 \mathrm{q} 3(\mathrm{n}=5), \operatorname{seg} 15 \mathrm{q} 2(\mathrm{n}=8))$, need to be validated ideally in large future studies - for their prognostic value.

After the search cut-off date imposed by the IPD meta-analysis criteria, another study was published recently focusing on CNS-PNET/pineoblastoma only in pediatric patients [17]. By evaluating the genomic array data which are available from NCBI's Gene Expression Omnibus (http://www.ncbi.nlm.nih.gov/geo/; accession number GSE12370), we were able to generate CNA profiles for 38 patients ( 8 of whom had pineoblastoma, and 30 had a CNS-PNET; CGH data from 35 CNS-PNET cases were listed, 5 recurrent tumors were paired with a primary sample from the same patient) and 1 CNS PNET cell line. Here, as in our IPD meta-analysis, pineoblastoma exhibited CNA profiles roughly comparable to subsets of cases identified as CNSPNET as shown in the Supplementary Figure $5 \mathrm{a}, \mathrm{b}$. 
The approach of an IPD meta-analysis - $\underline{\text { a specific method of systematic review based }}$ on a systematic search - is in our opinion both necessary and efficient to increase the patient number in rare tumor diseases. By using IPD we may overcome many of the limitations of systematic reviews (e.g. poor quality of data can be improved by updating the information). We used common inclusion and exclusion criteria for each individual case. In addition, we have performed a quality assessment of genomic data by reassessment of each individual case by two researchers (MB and HC). Methods to assess genomic CNAs are standardized and reproducible as demonstrated in previous reports (e.g. [11-12]). Moreover, by including unpublished data [25], we aimed to reduce the risk for publication bias [20]. Of course, the inclusion of a larger number of unpublished cases would have been desirable and a "pooling" of such data has an $\underline{\text { exceptional value for rare diseases. }}$. Of note, IPD meta-analyses usually takes longer than conventional systematic review, and obtaining IPD is time-consuming [20]. Therefore, it is not possible to include all very recent studies, and many IPD metaanalyses are conducted on a cyclical basis with data collection, quality assessment, analyses and dissemination of results taking place every few years [18], because by the time of the final analysis of the pooled data already new cases are available. We acknowledge some limitations of our study which is based on original data produced over a time period of several years. As shown in Supplementary Table 1, the WHO classification of tumors of the CNS has changed during this period. Moreover, in the recent years the staging has improved, as have surgical procedures and non-surgical treatment options of patients with CNS-PNET and tumors of the pineal region. Regarding genomic analysis methods, high-resolution profiling by genomic copy number arrays or whole genome sequencing could provide a higher sensitivity for the detection of hitherto undetected CNA. However, the main limitations in identifying 
robust CNA markers with prognostic value are in the limited number of samples and associated clinical datasets available for such analyses.

In summary, CNS-PNET and low grade tumors of the pineal region are characterized by differences in CNA profiles. In this respect, pineoblastoma fit readily into the genomically heterogeneous group of CNS-PNET with a complex karyotype. Although not necessarily displayed by each individual case, typical CNA profiles underline the differing biological background of these entities. Our results provide evidence that young age, high CNA complexity, and potentially also several specific CNAs may have an impact on OS.

\section{Competing interests}

The author(s) declare that they have no competing interests.

\section{Acknowledgements}

We are indebted to the authors of articles, who provided the data to this study that otherwise would not have been accessible. In particular we would like to thank the following researcher/clinicians for their help: Milo Puhan, Carolyn Russo, Wolfram Scheurlen, Barbara Schütz, Christine Haberler, Martin McCabe, and Hans-Hermann Dubben. We would like to thank Klaus-Dieter Papke for assisting the literature search. We acknowledge the following sources of funding: German Children's Cancer Foundation/Deutsche Kinderkrebsstiftung (to AOVB, SR). Haoyang Cai is supported through a grant from the China Scholarship Council. 


\section{References}

1 Gaffney CC, Sloane JP, Bradley NJ, Bloom HJ (1985) Primitive neuroectodermal tumours of the cerebrum. Pathology and treatment. J Neurooncol 3: 23-33

2 Li M, Lee KF, Lu Y, Clarke I, Shih D, Eberhart C, Collins VP, Van Meter T, Picard D, Zhou L, Boutros PC, Modena P, Liang ML, Scherer SW, Bouffet E, Rutka JT, Pomeroy SL, Lau CC, Taylor MD, Gajjar A, Dirks PB, Hawkins CE, Huang A (2009) Frequent amplification of a chr19q13.41 microRNA polycistron in aggressive primitive neuroectodermal brain tumors. Cancer Cell 16: $533-546$

3 Timmermann B, Kortmann RD, Kuhl J, Rutkowski S, Meisner C, Pietsch T, Deinlein F, Urban C, Warmuth-Metz M, Bamberg M (2006) Role of radiotherapy in supratentorial primitive neuroectodermal tumor in young children: results of the German HIT-SKK87 and HIT-SKK92 trials. J Clin Oncol 24: 1554-1560

4 Fangusaro J, Massimino M, Rutkowski S, Gururangan S (2010) Noncerebellar primitive neuroectodermal tumors (PNET): summary of the Milan consensus and state of the art workshop on marrow ablative chemotherapy with hematopoietic cell rescue for malignant brain tumors of childhood and adolescents. Pediatr Blood Cancer 54: 638-640

5 Louis DN, Ohgaki H, Wiestler OD, Cavenee WK (2007) WHO Classification of tumours of the central nervous system. IARC Press, Lyon

6 Vardiman JW, Thiele J, Arber DA, Brunning RD, Borowitz MJ, Porwit A, Harris NL, Le Beau MM, Hellstrom-Lindberg E, Tefferi A, Bloomfield CD (2009) The 2008 revision of the World Health Organization (WHO) classification of myeloid neoplasms and acute leukemia: rationale and important changes. Blood 114: 937-951

7 Kallioniemi A, Kallioniemi OP, Sudar D, Rutovitz D, Gray JW, Waldman F, Pinkel D (1992) Comparative genomic hybridization for molecular cytogenetic analysis of solid tumors. Science 258: 818-821

8 Joos S, Bergerheim US, Pan Y, Matsuyama H, Bentz M, du Manoir S, Lichter $\mathrm{P}$ (1995) Mapping of chromosomal gains and losses in prostate cancer by comparative genomic hybridization. Genes Chromosomes Cancer 14: 267-276

9 Solinas-Toldo S, Lampel S, Stilgenbauer S, Nickolenko J, Benner A, Dohner H, Cremer T, Lichter P (1997) Matrix-based comparative genomic hybridization: biochips to screen for genomic imbalances. Genes Chromosomes Cancer 20: 399-407

10 Pollack JR, Perou CM, Alizadeh AA, Eisen MB, Pergamenschikov A, Williams CF, Jeffrey SS, Botstein D, Brown PO (1999) Genome-wide analysis of DNA copy-number changes using cDNA microarrays. Nat Genet 23: $41-46$

11 Bown N, Cotterill S, Lastowska M, O'Neill S, Pearson AD, Plantaz D, Meddeb M, Danglot G, Brinkschmidt C, Christiansen H, Laureys G, Speleman F, Nicholson J, Bernheim A, Betts DR, Vandesompele J, Van Roy N (1999) Gain of chromosome arm 17q and adverse outcome in patients with neuroblastoma. N Engl J Med 340: 1954-1961 
12 Zenz T, Mertens D, Dohner H, Stilgenbauer S (2008) Molecular diagnostics in chronic lymphocytic leukemia - pathogenetic and clinical implications. Leuk Lymphoma 49: 864-873

13 Moinzadeh P, Breuhahn K, Stutzer H, Schirmacher P (2005) Chromosome alterations in human hepatocellular carcinomas correlate with aetiology and histological grade--results of an explorative CGH meta-analysis. Br J Cancer 92: 935-941

14 Baudis M (2007) Genomic imbalances in 5918 malignant epithelial tumors: an explorative meta-analysis of chromosomal CGH data. BMC Cancer 7: 226

15 Russo C, Pellarin M, Tingby O, Bollen AW, Lamborn KR, Mohapatra G, Collins VP, Feuerstein BG (1999) Comparative genomic hybridization in patients with supratentorial and infratentorial primitive neuroectodermal tumors. Cancer 86: 331-339

16 Pfister S, Remke M, Toedt G, Werft W, Benner A, Mendrzyk F, Wittmann A, Devens F, von Hoff K, Rutkowski S, Kulozik A, Radlwimmer B, Scheurlen W, Lichter P, Korshunov A (2007) Supratentorial primitive neuroectodermal tumors of the central nervous system frequently harbor deletions of the CDKN2A locus and other genomic aberrations distinct from medulloblastomas. Genes Chromosomes Cancer 46: 839-851

17 Miller S, Rogers HA, Lyon P, Rand V, Adamowicz-Brice M, Clifford SC, Hayden JT, Dyer S, Pfister S, Korshunov A, Brundler MA, Lowe J, Coyle B, Grundy RG (2011) Genome-wide molecular characterization of central nervous system primitive neuroectodermal tumor and pineoblastoma. Neuro Oncol 13: 866-879

18 Clarke M, Godwin J (1998) Systematic reviews using individual patient data: a map for the minefields? Ann Oncol 9: 827-833

19 Riley RD, Sauerbrei W, Altman DG (2009) Prognostic markers in cancer: the evolution of evidence from single studies to meta-analysis, and beyond. $\mathrm{Br} \mathrm{J}$ Cancer 100: 1219-1229

20 Altman DG (2001) Systematic reviews of evaluations of prognostic variables. BMJ 323: 224-228

21 Baudis M, Cleary ML (2001) Progenetix.net: an online repository for molecular cytogenetic aberration data. Bioinformatics 17: 1228-1229

22 Baudis M (2006) Online database and bioinformatics toolbox to support data mining in cancer cytogenetics. Biotechniques 40: 269-270, 272

23 Wilne S, Collier J, Kennedy C, Koller K, Grundy R, Walker D (2007) Presentation of childhood CNS tumours: a systematic review and metaanalysis. Lancet Oncol 8: 685-695

24 Moher D, Liberati A, Tetzlaff J, Altman DG (2009) Preferred reporting items for systematic reviews and meta-analyses: the PRISMA statement. PLoS Med 6: e1000097

25 Stewart LA, Tierney JF (2002) To IPD or not to IPD? Advantages and disadvantages of systematic reviews using individual patient data. Eval Health Prof 25: 76-97

26 Simmonds MC, Higgins JP, Stewart LA, Tierney JF, Clarke MJ, Thompson SG (2005) Meta-analysis of individual patient data from randomized trials: a review of methods used in practice. Clin Trials 2: 209-217

27 Boerma EG, Siebert R, Kluin PM, Baudis M (2009) Translocations involving 8 q24 in Burkitt lymphoma and other malignant lymphomas: a historical 
review of cytogenetics in the light of todays knowledge. Leukemia 23: 225234

28 LeBlanc M, Crowley J (1992) Relative risk trees for censored survival data. Biometrics 48: 411-425

29 Kaplan EL, Meier P (1958) Nonparametric estimation from incomplete observations. J Am Stat Assoc 53: 457-481

30 Kleihues P, Cavenee WK (2000) World Health Organization Classification of Tumours. Pathology and genetics of tumours of the nervous system. IARC Press, Lyon

31 Eberhart CG, Brat DJ, Cohen KJ, Burger PC (2000) Pediatric neuroblastic brain tumors containing abundant neuropil and true rosettes. Pediatr Dev Pathol 3: 346-352

32 Paulus W, Kleihues P (2010) Genetic profiling of CNS tumors extends histological classification. Acta Neuropathol 120: 269-270

33 Korshunov A, Remke M, Gessi M, Ryzhova M, Hielscher T, Witt H, Tobias V, Buccoliero AM, Sardi I, Gardiman MP, Bonnin J, Scheithauer B, Kulozik AE, Witt O, Mork S, von Deimling A, Wiestler OD, Giangaspero F, Rosenblum M, Pietsch T, Lichter P, Pfister SM (2010) Focal genomic amplification at $19 \mathrm{q} 13.42$ comprises a powerful diagnostic marker for embryonal tumors with ependymoblastic rosettes. Acta Neuropathol 120: 253260

34 Schwalbe EC, Lindsey JC, Straughton D, Hogg TL, Cole M, Megahed H, Ryan SL, Lusher ME, Taylor MD, Gilbertson RJ, Ellison DW, Bailey S, Clifford SC (2011) Rapid diagnosis of medulloblastoma molecular subgroups. Clin Cancer Res 17: 1883-1894

35 Thompson MC, Fuller C, Hogg TL, Dalton J, Finkelstein D, Lau CC, Chintagumpala M, Adesina A, Ashley DM, Kellie SJ, Taylor MD, Curran T, Gajjar A, Gilbertson RJ (2006) Genomics identifies medulloblastoma subgroups that are enriched for specific genetic alterations. J Clin Oncol 24: 1924-1931

36 Kool M, Koster J, Bunt J, Hasselt NE, Lakeman A, van Sluis P, Troost D, Meeteren NS, Caron HN, Cloos J, Mrsic A, Ylstra B, Grajkowska W, Hartmann W, Pietsch T, Ellison D, Clifford SC, Versteeg R (2008) Integrated genomics identifies five medulloblastoma subtypes with distinct genetic profiles, pathway signatures and clinicopathological features. PLoS One 3: e3088

37 Cho YJ, Tsherniak A, Tamayo P, Santagata S, Ligon A, Greulich H, Berhoukim R, Amani V, Goumnerova L, Eberhart CG, Lau CC, Olson JM, Gilbertson RJ, Gajjar A, Delattre O, Kool M, Ligon K, Meyerson M, Mesirov JP, Pomeroy SL (2011) Integrative genomic analysis of medulloblastoma identifies a molecular subgroup that drives poor clinical outcome. J Clin Oncol 29: 1424-1430

38 Northcott PA, Korshunov A, Witt H, Hielscher T, Eberhart CG, Mack S, Bouffet E, Clifford SC, Hawkins CE, French P, Rutka JT, Pfister S, Taylor MD (2011) Medulloblastoma comprises four distinct molecular variants. J Clin Oncol 29: 1408-1414

39 Remke M, Hielscher T, Northcott PA, Witt H, Ryzhova M, Wittmann A, Benner A, von Deimling A, Scheurlen W, Perry A, Croul S, Kulozik AE, Lichter P, Taylor MD, Pfister SM, Korshunov A (2011) Adult 
medulloblastoma comprises three major molecular variants. J Clin Oncol 29: 2717-2723

Remke M, Hielscher T, Korshunov A, Northcott PA, Bender S, Kool M, Westermann F, Benner A, Cin H, Ryzhova M, Sturm D, Witt H, Haag D, Toedt G, Wittmann A, Schottler A, von Bueren AO, von Deimling A, Rutkowski S, Scheurlen W, Kulozik AE, Taylor MD, Lichter P, Pfister SM (2011) FSTL5 Is a Marker of Poor Prognosis in Non-WNT/Non-SHH Medulloblastoma. J Clin Oncol 29: 3852-3861

41 Taylor MD, Northcott PA, Korshunov A, Remke M, Cho YJ, Clifford SC, Eberhart CG, Parsons DW, Rutkowski S, Gajjar A, Ellison DW, Lichter P, Gilbertson RJ, Pomeroy SL, Kool M, Pfister SM (2012) Molecular subgroups of medulloblastoma: the current consensus. Acta Neuropathol 123: 465-472

42 Kool M, Korshunov A, Remke M, Jones DT, Schlanstein M, Northcott PA, Cho YJ, Koster J, Schouten-van Meeteren A, van Vuurden D, Clifford SC, Pietsch T, von Bueren AO, Rutkowski S, McCabe M, Collins VP, Backlund ML, Haberler C, Bourdeaut F, Delattre O, Doz F, Ellison DW, Gilbertson RJ, Pomeroy SL, Taylor MD, Lichter P, Pfister SM (2012) Molecular subgroups of medulloblastoma: an international meta-analysis of transcriptome, genetic aberrations, and clinical data of WNT, SHH, Group 3, and Group 4 medulloblastomas. Acta Neuropathol 123: 473-484

43 Geyer JR, Sposto R, Jennings M, Boyett JM, Axtell RA, Breiger D, Broxson E, Donahue B, Finlay JL, Goldwein JW, Heier LA, Johnson D, Mazewski C, Miller DC, Packer R, Puccetti D, Radcliffe J, Tao ML, Shiminski-Maher T (2005) Multiagent chemotherapy and deferred radiotherapy in infants with malignant brain tumors: a report from the Children's Cancer Group. J Clin Oncol 23: 7621-7631

44 Pizer BL, Weston CL, Robinson KJ, Ellison DW, Ironside J, Saran F, Lashford LS, Tait D, Lucraft H, Walker DA, Bailey CC, Taylor RE (2006) Analysis of patients with supratentorial primitive neuro-ectodermal tumours entered into the SIOP/UKCCSG PNET 3 study. Eur J Cancer 42: 1120-1128

45 Timmermann B, Kortmann RD, Kuhl J, Meisner C, Dieckmann K, Pietsch T, Bamberg M (2002) Role of radiotherapy in the treatment of supratentorial primitive neuroectodermal tumors in childhood: results of the prospective German brain tumor trials HIT 88/89 and 91. J Clin Oncol 20: 842-849 Li MH, Bouffet E, Hawkins CE, Squire JA, Huang A (2005) Molecular genetics of supratentorial primitive neuroectodermal tumors and pineoblastoma. Neurosurg Focus 19: E3 


\section{Figure legends}

\section{Fig. 1 Delineation of 3 distinct clinicogenetic subgroups}

a Regional copy number imbalances for individual cases were plotted separately by overall diagnostic assignment (yellow: gain; blue: loss; blue: tumors of the pineal region except pineoblastoma; light blue: pineoblastoma; pink: central primitive neuroectodermal tumors (CNS-PNET)). Individual profiles were arranged by hierarchical clustering inside their groups. b Histograms of genomic gain and loss frequencies (color legend corresponding to (a)). 
Tables

Table 1 Demographics and disease characteristics of 61 patients with Central Primitive Neuroectodermal Tumors (CNS-PNET) and Tumors of the Pineal Region

\begin{tabular}{|l|c|}
\hline \multicolumn{1}{|c|}{ Characteristics } & $\begin{array}{c}\text { Number of patients (complete } \\
\text { follow-up; n=61) }\end{array}$ \\
\hline Sex & $21(21 \%)$ \\
\hline Male & $17(28 \%)$ \\
\hline Female & $31(51 \%)$ \\
\hline N/A & $2.2(0.6-66)$ \\
\hline Age & $21(35 \%)$ \\
\hline Median age at diagnosis (range; years) & $32(52 \%)$ \\
\hline Histology & $15(25 \%)$ \\
\hline CNS-PNET & $2(4 \%)$ \\
\hline Tumors of the pineal region & \\
\hline Tumor samples source & \\
\hline Primary tumors & \\
\hline Relapses & \\
\hline Netastatic stage & \\
\hline Metastases & \\
\hline
\end{tabular}

N/A, information not available 
Table 2 Multivariable analyses of clinical prognostic factors $(n=61)$ for overall survival $(\mathrm{OS})$

\begin{tabular}{|c|c|c|c|c|c|}
\hline Parameter & Comparison & Sample size & HR OS & $\begin{array}{l}95 \% \text { Confidence } \\
\text { interval }(\mathrm{CI})\end{array}$ & p-value \\
\hline \multirow{3}{*}{ Histology } & Non CNS-PNET & 15 & \multirow{3}{*}{0.312} & \multirow{3}{*}{$0.109-0.891$} & \multirow{3}{*}{0.0296} \\
\hline & & & & & \\
\hline & CNS-PNET & 46 & & & \\
\hline \multirow{3}{*}{ Age group (years) } & $>2.5$ & 46 & \multirow{3}{*}{0.386} & \multirow{3}{*}{$0.197-0.757$} & \multirow{3}{*}{0.0056} \\
\hline & & & & & \\
\hline & $\leqslant 2.5$ & 15 & & & \\
\hline \multirow{3}{*}{ CNA complexity } & $\notin 11 \mathrm{CNA}$ & 23 & \multirow{3}{*}{1.790} & \multirow{3}{*}{$0.943-3.400$} & \multirow{3}{*}{0.0752} \\
\hline & & & & & \\
\hline & $<11 \mathrm{CNA}$ & 38 & & & \\
\hline
\end{tabular}

CNS-PNET, Central primitive neuroectodermal tumor; Non CNS-PNET, tumors of the pineal region; CNA, copy number aberrations; HR OS, Hazard ratio overall survival 
Table 3 Multivariable analyses of clinical factors and recurrent chromosomal aberrations (forward stepwise selection; $\mathbf{n = 6 1}$ ) for overall survival (OS)

\begin{tabular}{|l|l|l|l|l|}
\hline Parameter & sample size & $\begin{array}{l}\text { Hazard ratio } \\
\text { overall survival } \\
\text { (OS) }\end{array}$ & $\begin{array}{l}\text { 95\% Confidence } \\
\text { interval (CI) }\end{array}$ & -value \\
\hline Age $(\geq 2.5$ years) & 46 & 0.295 & $0.141-0.619$ & 0.0012 \\
\hline $\begin{array}{l}\text { Histology (tumor of the pineal } \\
\text { region) }\end{array}$ & 15 & 0.120 & $0.029-0.498$ & 0.0048 \\
\hline seg3p1_gain & 3 & 8.759 & $1.778-43.159$ & 0.0077 \\
\hline seg13q3_gain & 5 & 4.128 & $1.192-14.303$ & 0.0253 \\
\hline seg15q2_gain & 8 & 4.338 & $1.614-11.665$ & 0.0036 \\
\hline
\end{tabular}




\section{Supplementary Table 1 WHO Classification of Tumors of the Nervous}

\section{System 1993-2007: Embryonal Tumors}

\begin{tabular}{|c|c|c|c|}
\hline WHO 1993 & WHO 1997 & WHO 2000 & WHO 2007 \\
\hline $\begin{array}{l}\text { Medulloblastoma } \\
\text { Medullomyoblastoma } \\
\text { Melanotic MB } \\
\text { Desmoplastic MB }\end{array}$ & $\begin{array}{l}\text { Medulloblastoma } \\
\text { Medullomyoblastoma } \\
\text { Melanotic MB } \\
\text { Desmoplastic MB } \\
\text { MB with extensive } \\
\text { nodularity } \\
\text { Large cell MB } \\
\text { Lipomatous MB }\end{array}$ & $\begin{array}{l}\text { Medulloblastoma } \\
\text { Medullomyoblastoma } \\
\text { Melanotic MB } \\
\text { Desmoplastic MB } \\
\text { MB with extensive } \\
\text { nodularity } \\
\text { Large cell MB }\end{array}$ & $\begin{array}{l}\text { Medulloblastoma } \\
\text { Desmoplastic / nodular } \\
\text { MB } \\
\text { MB with extensive } \\
\text { nodularity } \\
\text { Large cell MB } \\
\text { Anaplastic MB }\end{array}$ \\
\hline $\begin{array}{l}\text { Primitive } \\
\text { neuroectoderma tumor } \\
(\mathrm{PNET})\end{array}$ & $\begin{array}{l}\text { Supratentorial PNET } \\
\text { (sPNET) }\end{array}$ & $\begin{array}{l}\text { Supratentorial PNET } \\
\text { (sPNET) } \\
\text { Neuroblastoma } \\
\text { Ganglio-neuroblastoma }\end{array}$ & $\begin{array}{l}\text { CNS-PNET } \\
\text { CNS Neuroblastoma } \\
\text { CNS Ganglio- } \\
\text { neuroblastoma } \\
\text { Medulloepithelioma } \\
\text { Ependymoblastoma }\end{array}$ \\
\hline $\begin{array}{l}\text { Neuroblastoma } \\
\text { Ganglio-neuroblastoma }\end{array}$ & $\begin{array}{l}\text { Central neuroblastoma } \\
\text { Ganglio-neuroblastoma }\end{array}$ & & \\
\hline Medulloepithelioma & Medulloepithelioma & Medulloepithelioma & \\
\hline Ependymoblastoma & Ependymoblastoma & Ependymoblastoma & \\
\hline & $\begin{array}{l}\text { Atypical } \\
\text { teratoid/rhabdoid tumor }\end{array}$ & $\begin{array}{l}\text { Atypical } \\
\text { teratoid/rhabdoid tumor }\end{array}$ & $\begin{array}{l}\text { Atypical } \\
\text { teratoid/rhabdoid tumor }\end{array}$ \\
\hline
\end{tabular}

MB, medulloblastoma; CNS, Central nervous system; PNET, primitive neuroectodermal tumor 
Supplementary Table 2: Overall survival (OS) according to clinical factors and

\begin{tabular}{|l|l|l|l|l|}
\hline Parameter & Comparison & Sample size & 7-year OS (\%) & p-value \\
\hline \multirow{3}{*}{ Histology } & CNS-PNET & 46 & 22.9 & \multirow{2}{*}{0.007} \\
\cline { 2 - 5 } & Non CNS-PNET & 15 & 64.7 & \\
\hline \multirow{2}{*}{$\begin{array}{l}\text { (ye group } \\
\text { years) }\end{array}$} & 2.5 & 15 & 0.0 & \multirow{2}{*}{0.001} \\
\cline { 2 - 5 } & 2.5 & 46 & 41.3 & \\
\hline \multirow{2}{*}{ CNA complexity } & $11 \mathrm{CNA}$ & 38 & 39.9 & \multirow{2}{*}{0.057} \\
\cline { 2 - 5 } & $211 \mathrm{CNA}$ & 23 & 19.6 & \\
\hline
\end{tabular}

CNS-PNET, Central primitive neuroectodermal tumor; Non CNS-PNET, tumors of the pineal region; CNA, copy number aberrations; OS, overall survival 


\title{
Supplementary Figure legends
}

Supplementary Fig. $1 \quad$ Flow chart of study selection process.

CNS, Central nervous system; PNET, primitive neuroectodermal tumor

\section{Supplementary Fig. 2 Overall imbalance frequencies in 107 tumors of} different histological classifications (low grade tumors of the pineal region, $n=13$; pineoblastoma, $n=6$; CNS-PNET, $n=88$ )

a Histogram: green/up: percent of cases with copy number gain in corresponding region; red/down: percent of cases with losses. b Gain/loss profile overview: comparison of the normalized gain/loss frequencies for the different entities (i.e. the highest value for either gain or loss leads to a maximum color intensity of the respective green or red color channel)

\author{
Supplementary Fig. $3 \quad$ International Classification of Diseases (ICD) \\ mapped subset profiles for CNS-PNET and pineoblastoma \\ a CNS-PNET, NOS tumors (ICD-O 9473/3; 77 cases). b Ependymoblastoma (ICD-O \\ 9392/3; 9 cases). c Medulloepithelioma (ICD-O 9501/3; 2 cases). d Pineoblastoma \\ (ICD-O 9362/3; 6 cases).
}




\author{
Supplementary Fig. 4 International Classification of Diseases (ICD) \\ mapped subset profiles for low grade tumors of the pineal region \\ a Papillary tumors of the pineal region (ICD-O 9395/3; 5 cases). b Pineal \\ parenchymal tumors of intermediate differentiation (ICD-O 9362/3; 3 cases). c \\ Pineocytoma (ICD-O 9361/1; 5 cases)
}

Supplementary Fig. 5 Comparison dataset (Miller et al. [17], PMID 21798848)

a Case specific gain/loss regions sorted for 8 pineoblastoma and 31 CNS-PNET cases (one cell line) extracted from PMID 21798848. b Frequency profiles of the case groups in Supplementary Figure 4A.

\title{
Supplementary Fig. $6 \quad$ Focal amplification at chromosome 19q
}

a Gains (yellow)/losses (blue) in 9 cases with focal amplification at 19q1.

Remarkably, 8/9 cases also display gains of at least parts of chromosome 2, a feature observed also in a subset of other CNS-PNET tumors. b Three example plots of the amplified region on chromosome $19 q 1$, generated from data available through the GEO deposit GSE14087 (Li et al. [2], PMID 19962671). Of note is the apparently complex structure of the region in GSM353483 and GSM353447. 
Figure 1

Click here to download high resolution image

A

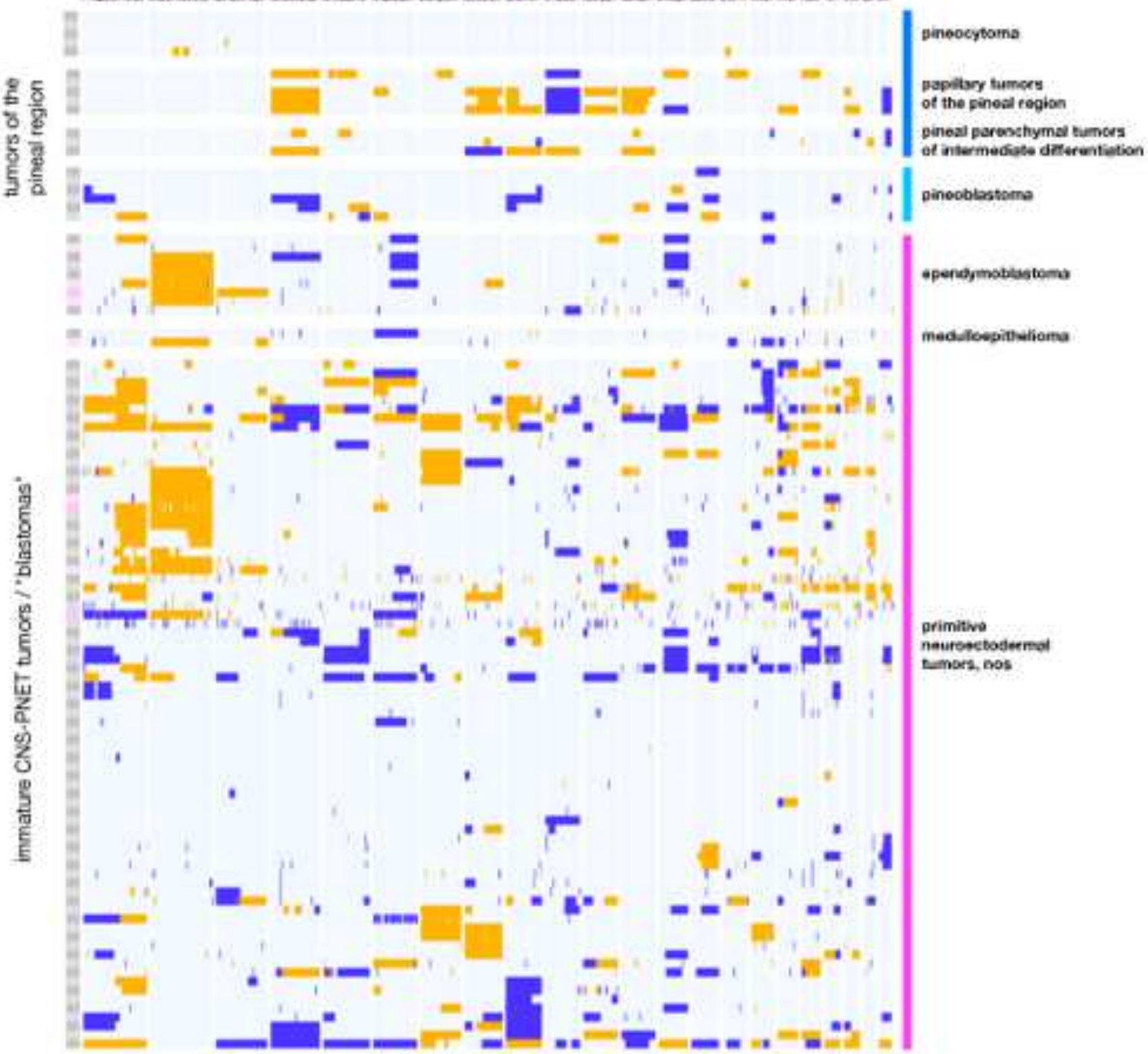

B

ta

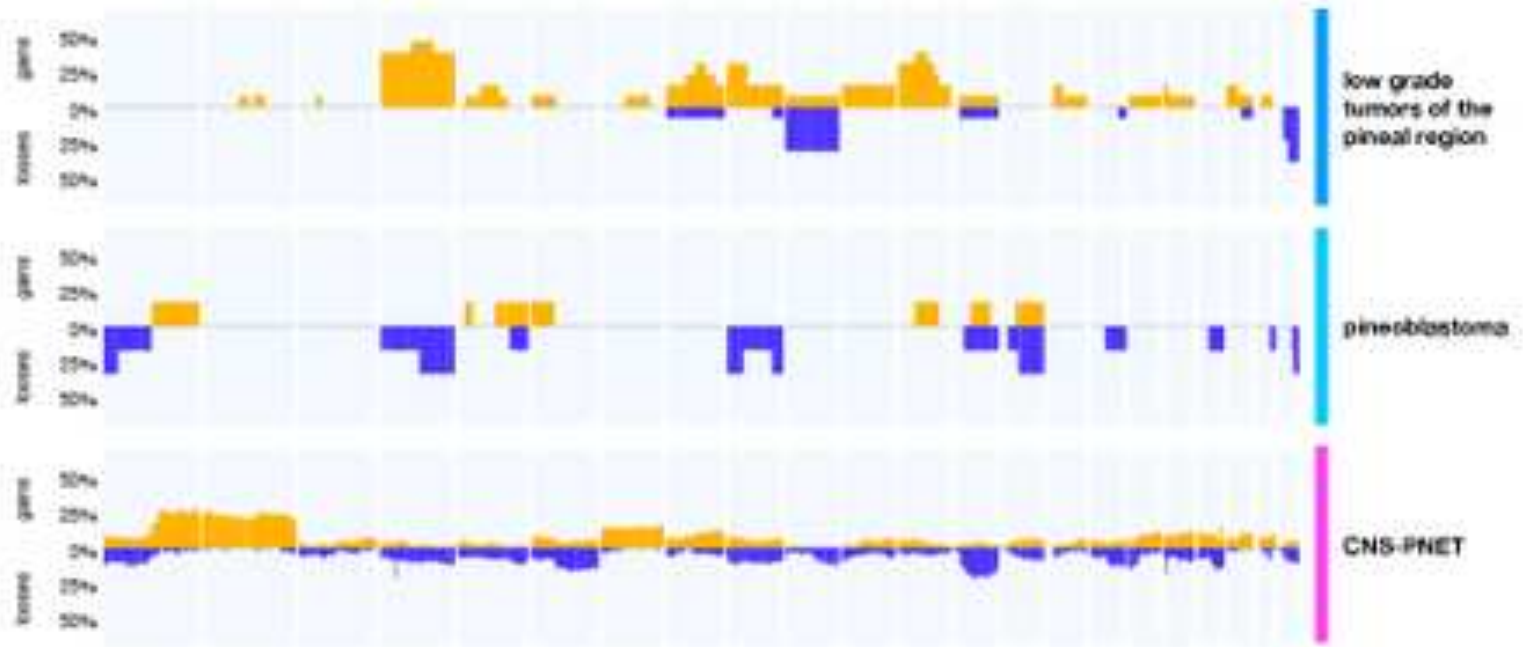


MEDLINE, PubMed, and EMBASE searched

from January, 1992, to July, 2010

Potentially relevant studies

$$
n=1220
$$
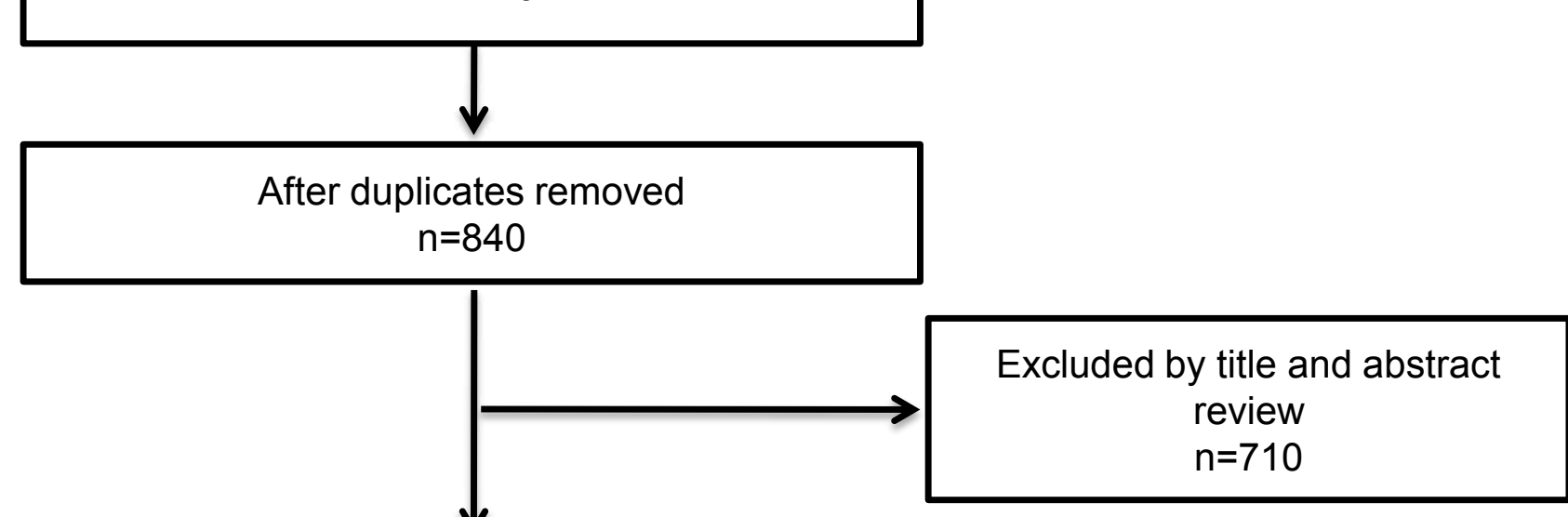

Full copies retrieved and assessed for eligibility $n=130$

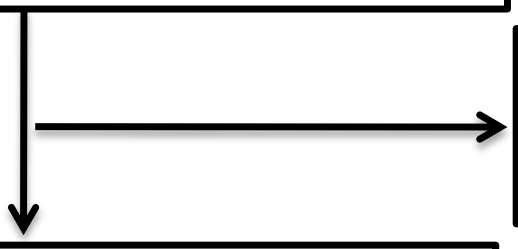

Excluded, not eligible

for this study

$$
\mathrm{n}=115
$$

Studies included in meta-analysis

( $n=15,104$ patients)

Study identified from contact with experts (3 unpublished CNS-PNET)

Studies included in meta-analysis ( $n=16,107$ patients (exclusion of 4 cases); 61 patients with information about overall survival) 
Figure S2a

CNS-PNET and tumors of the pinealis region (107 cases)

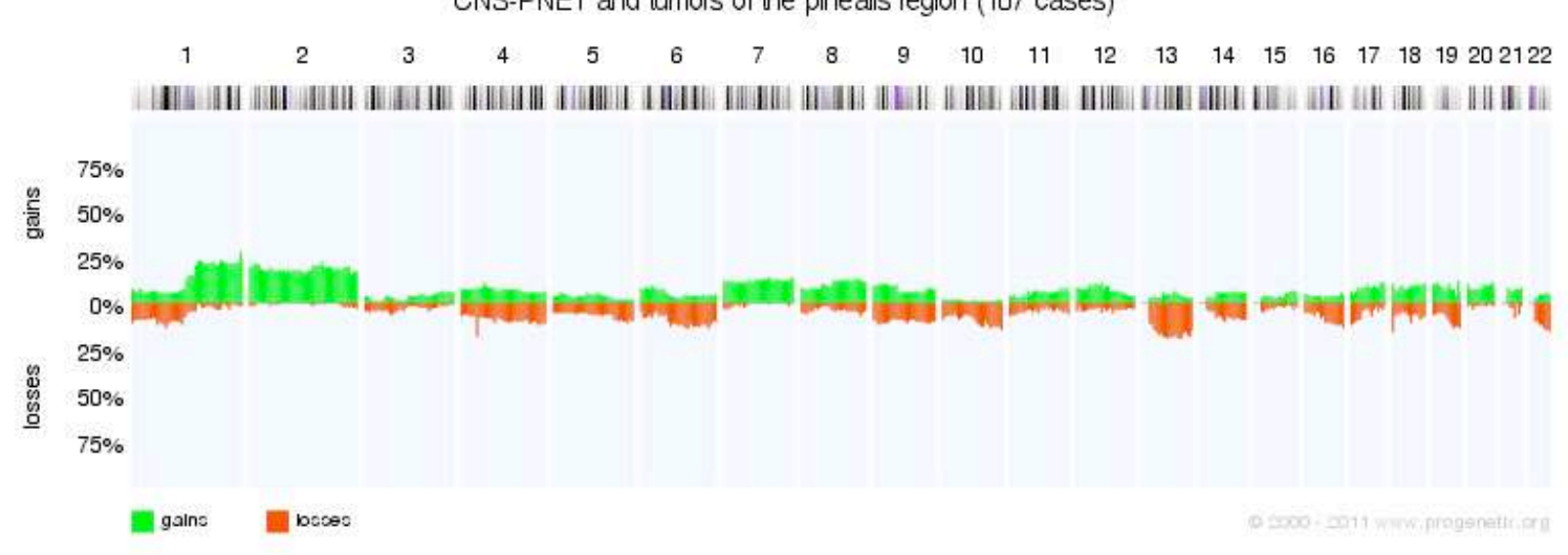

Figure S2b

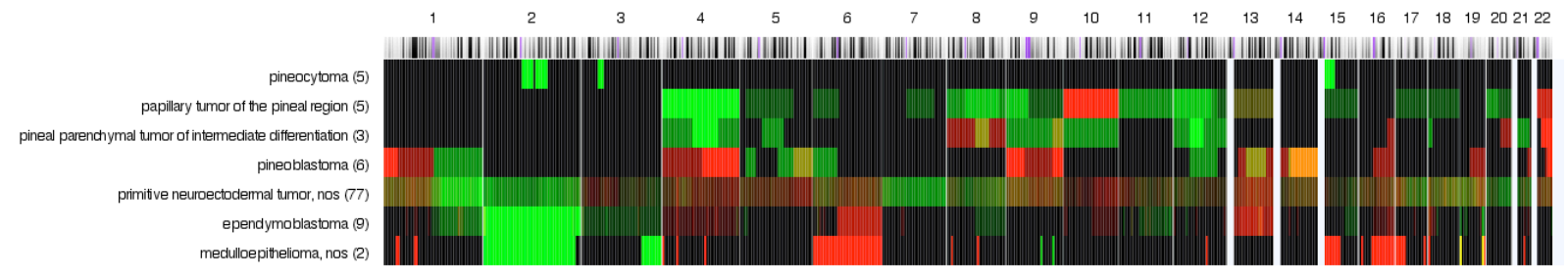




\section{Figure S3a}

CNS-PNET and tumors of the pinealis region (primitive neuroectodermal tumor, nos, 77 cases)

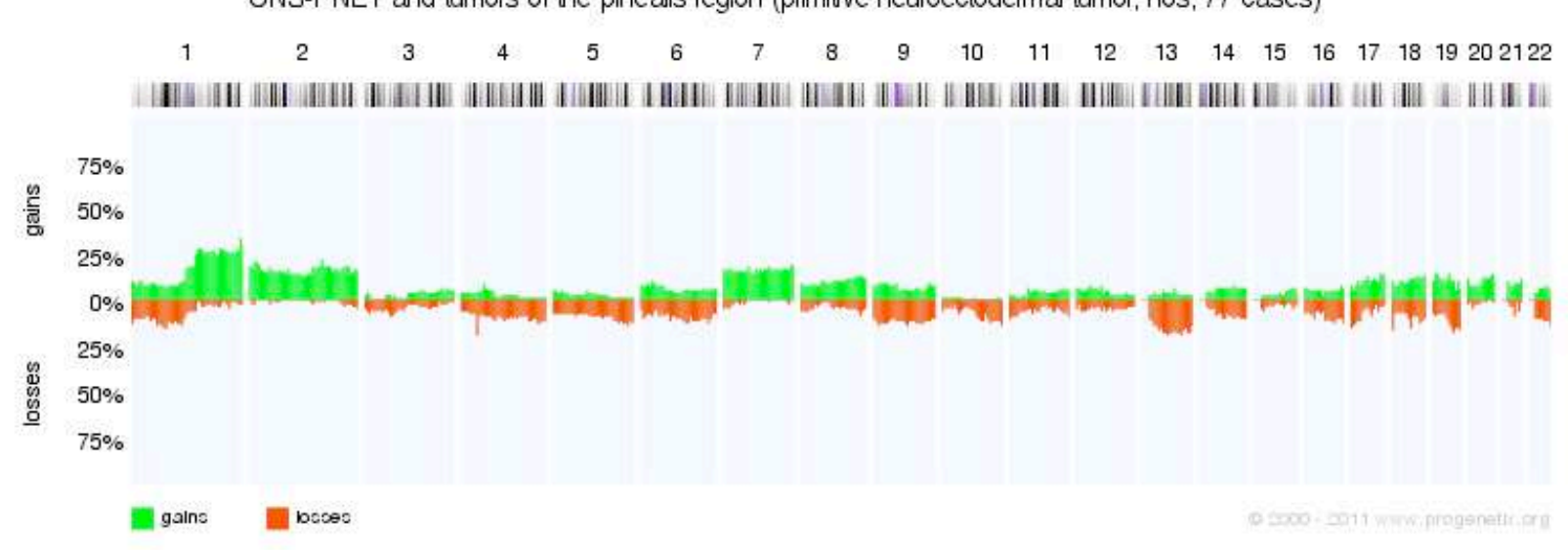

\section{Figure S3b}

CNS-PNET and tumors of the pinealis region (ependymoblastoma, 9 cases)

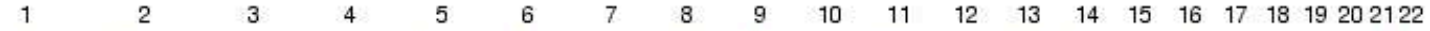

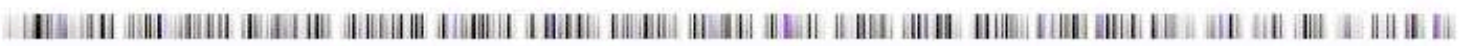

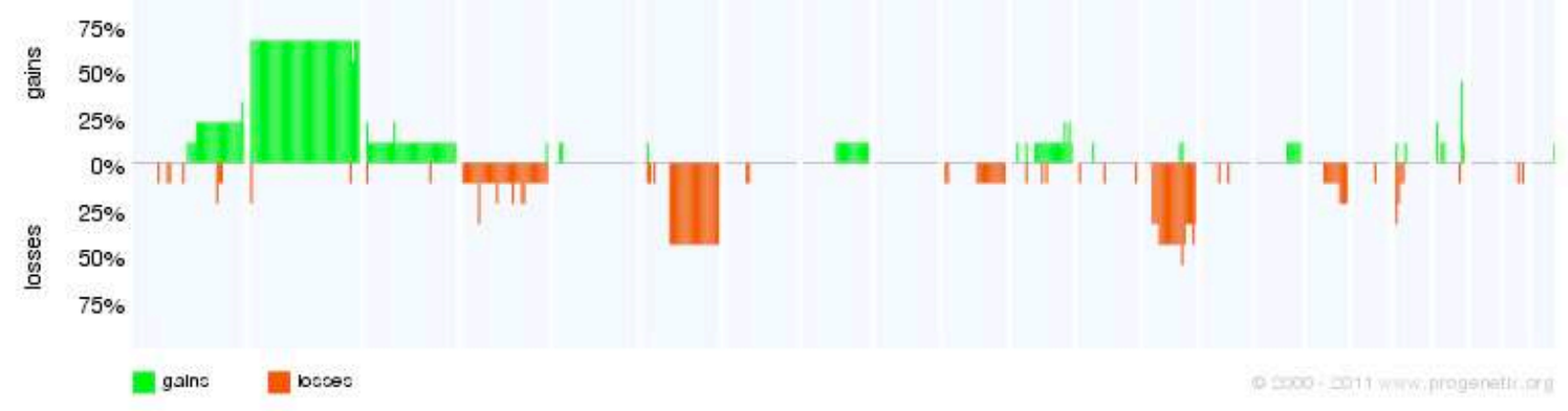


Figure S3c

CNS-PNET and tumors of the pinealis region (medulloepithelioma, nos, 2 cases)

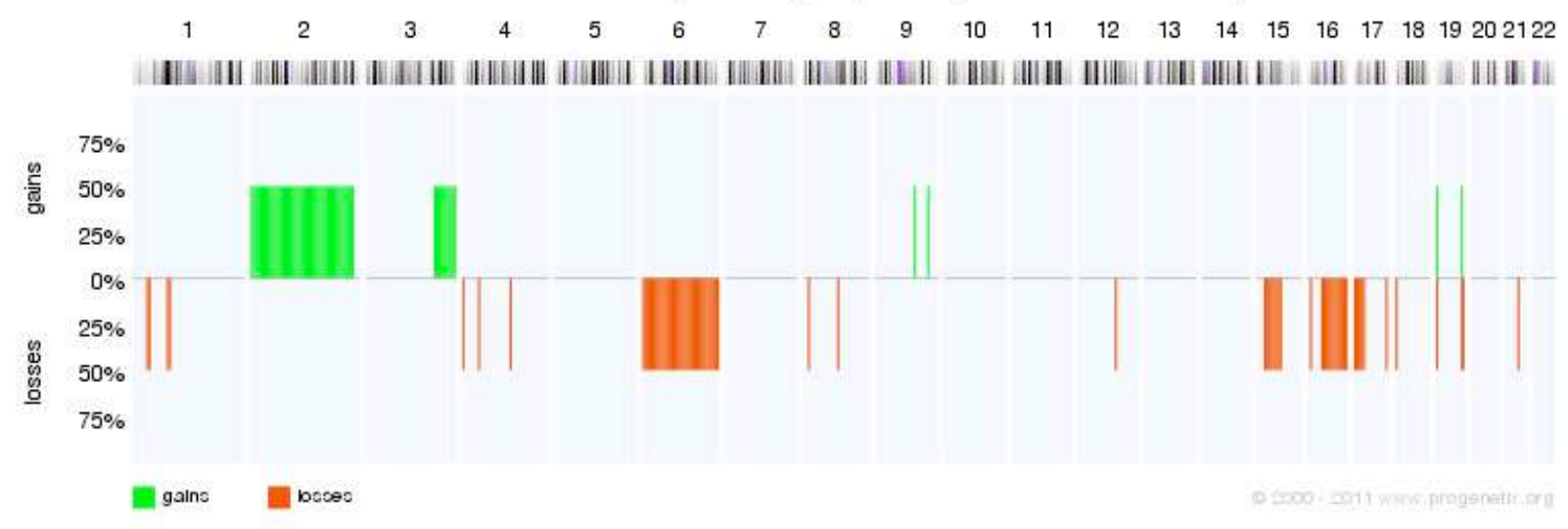

Figure S3d

CNS-PNET and tumors of the pinealis region (pineoblastoma, 6 cases)

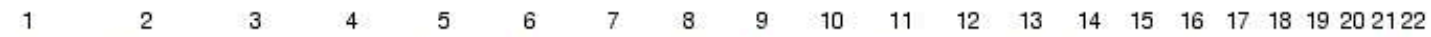

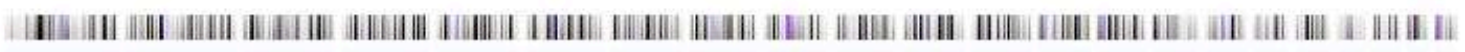

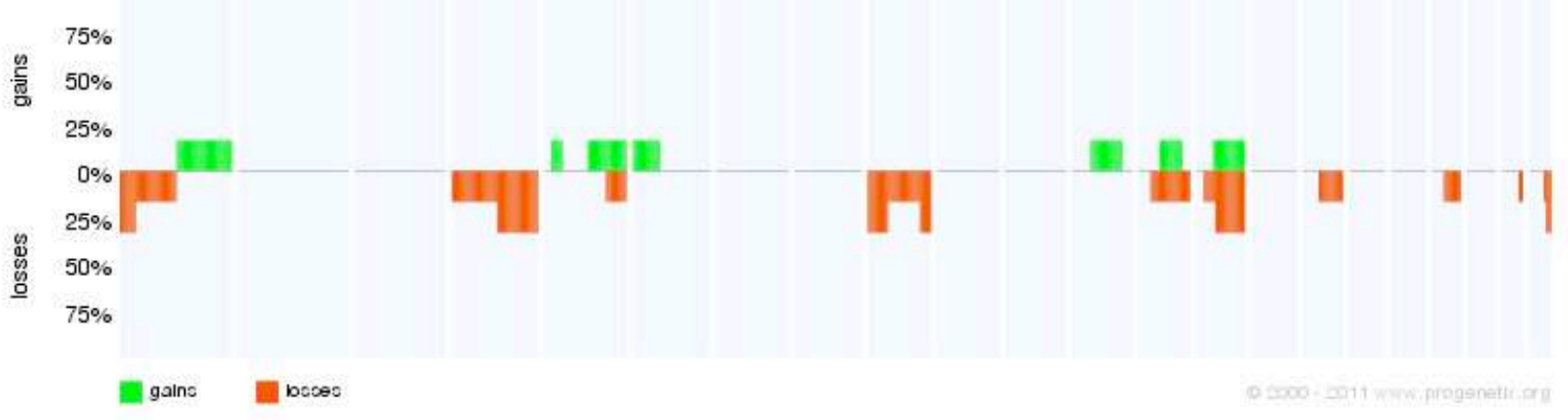




\section{Figure S4a}

CNS-PNET and tumors of the pinealis region (papillary tumor of the pineal region, 5 cases)

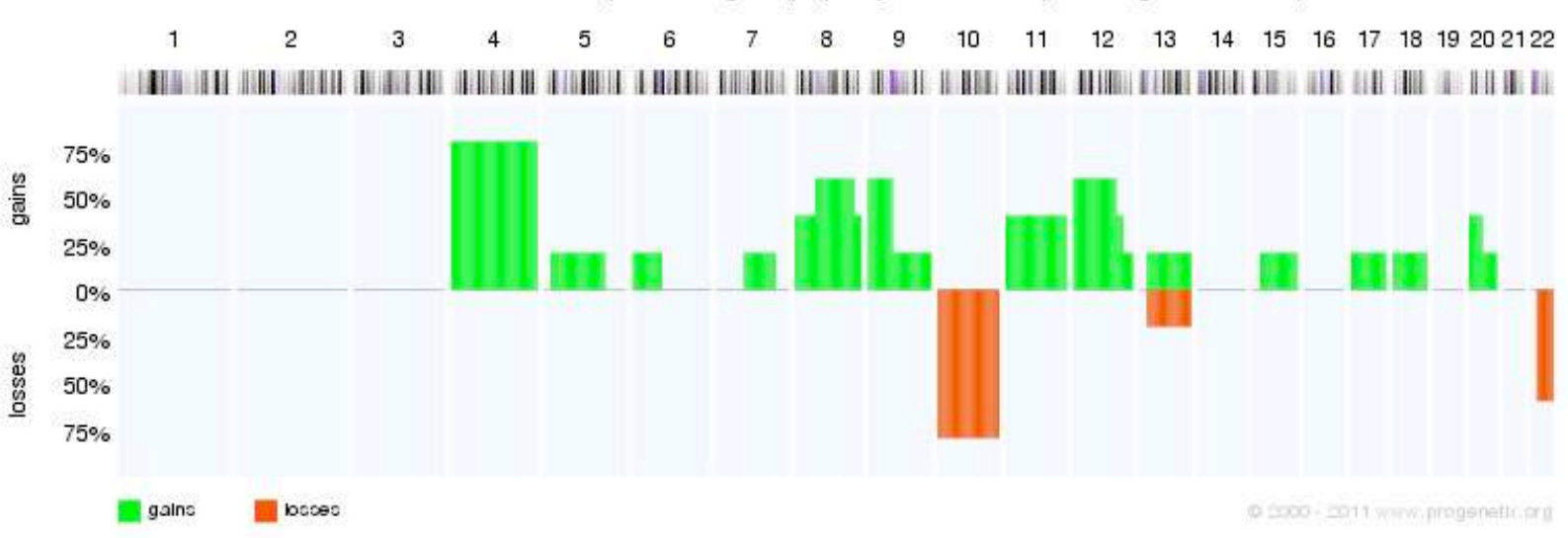

Figure S4b

CNS-PNET and tumors of the pinealis region (pineal parenchymal tumor of intermediate differentiation, 3 cases)

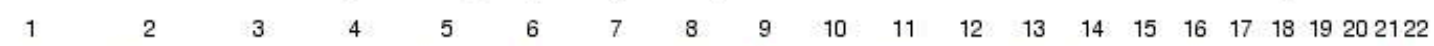

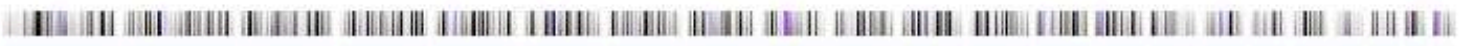

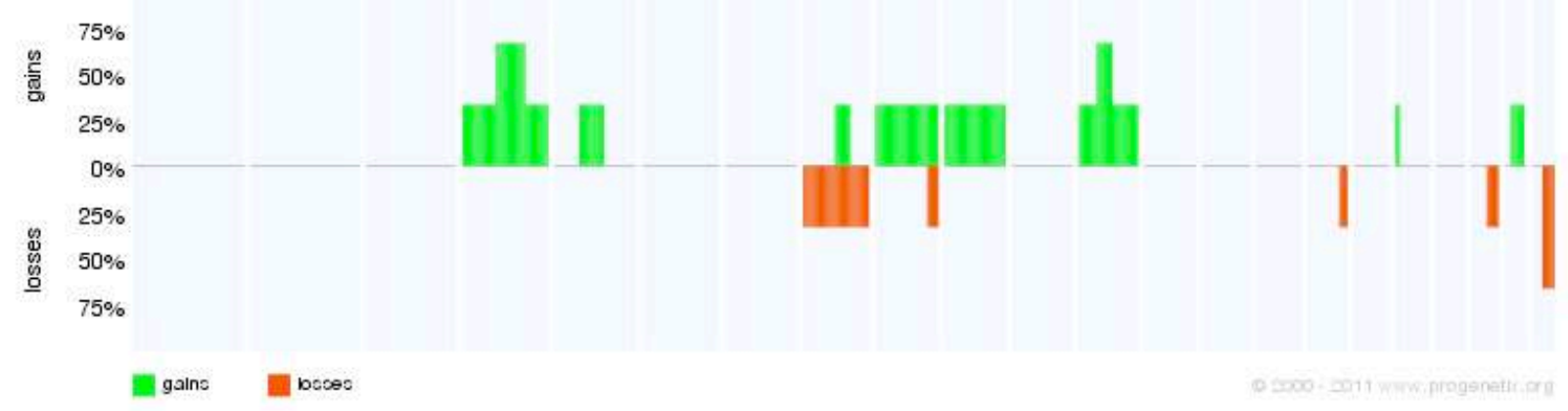

Figure S4c

CNS-PNET and tumors of the pinealis region (pineocytoma, 5 cases)

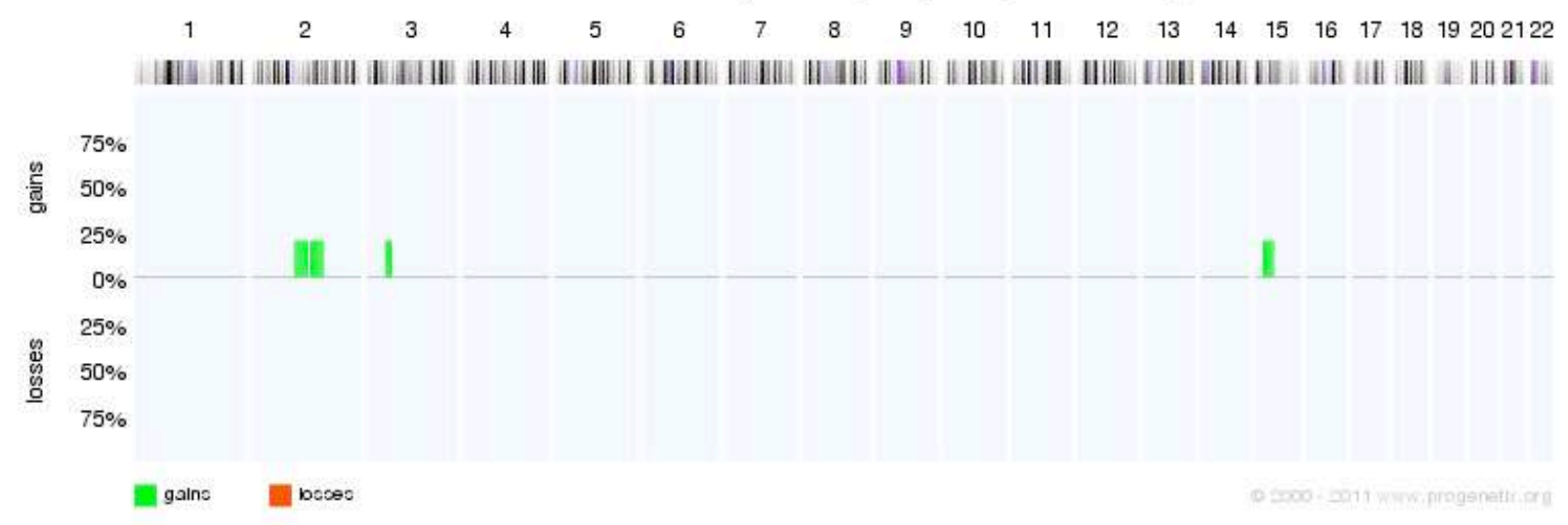


Figure S5a

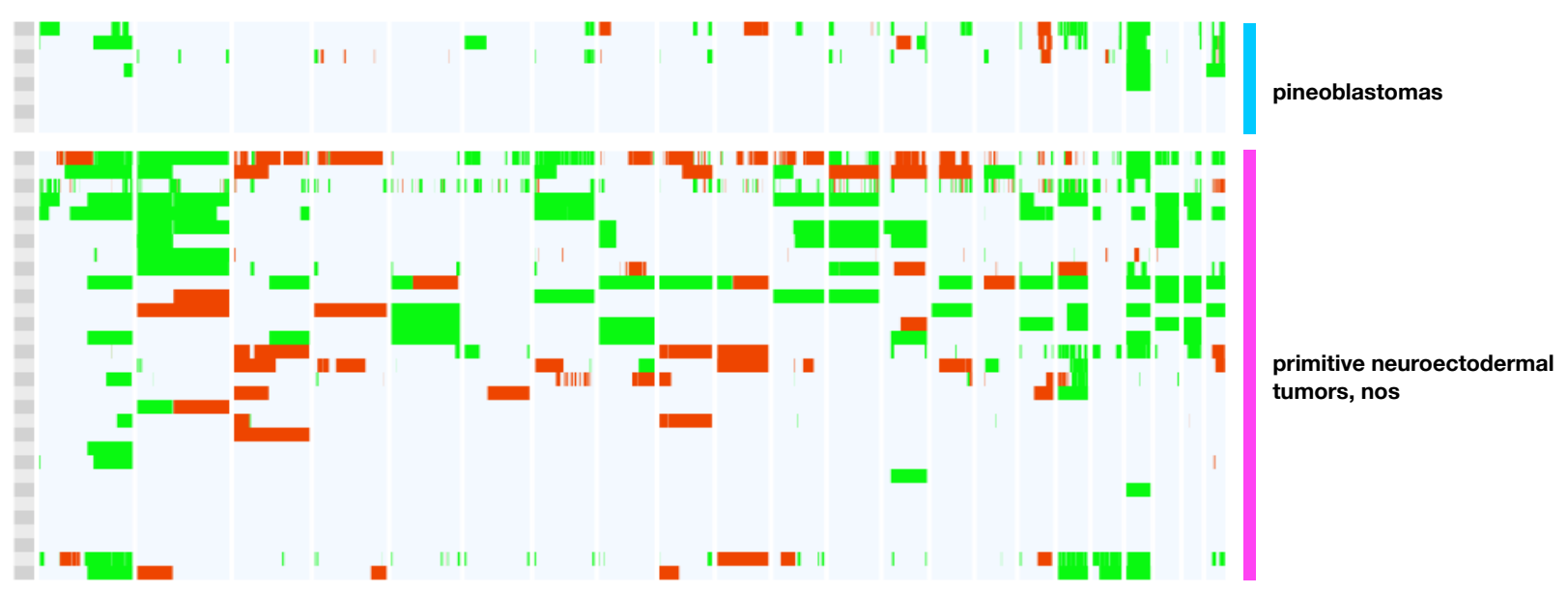

Figure S5b

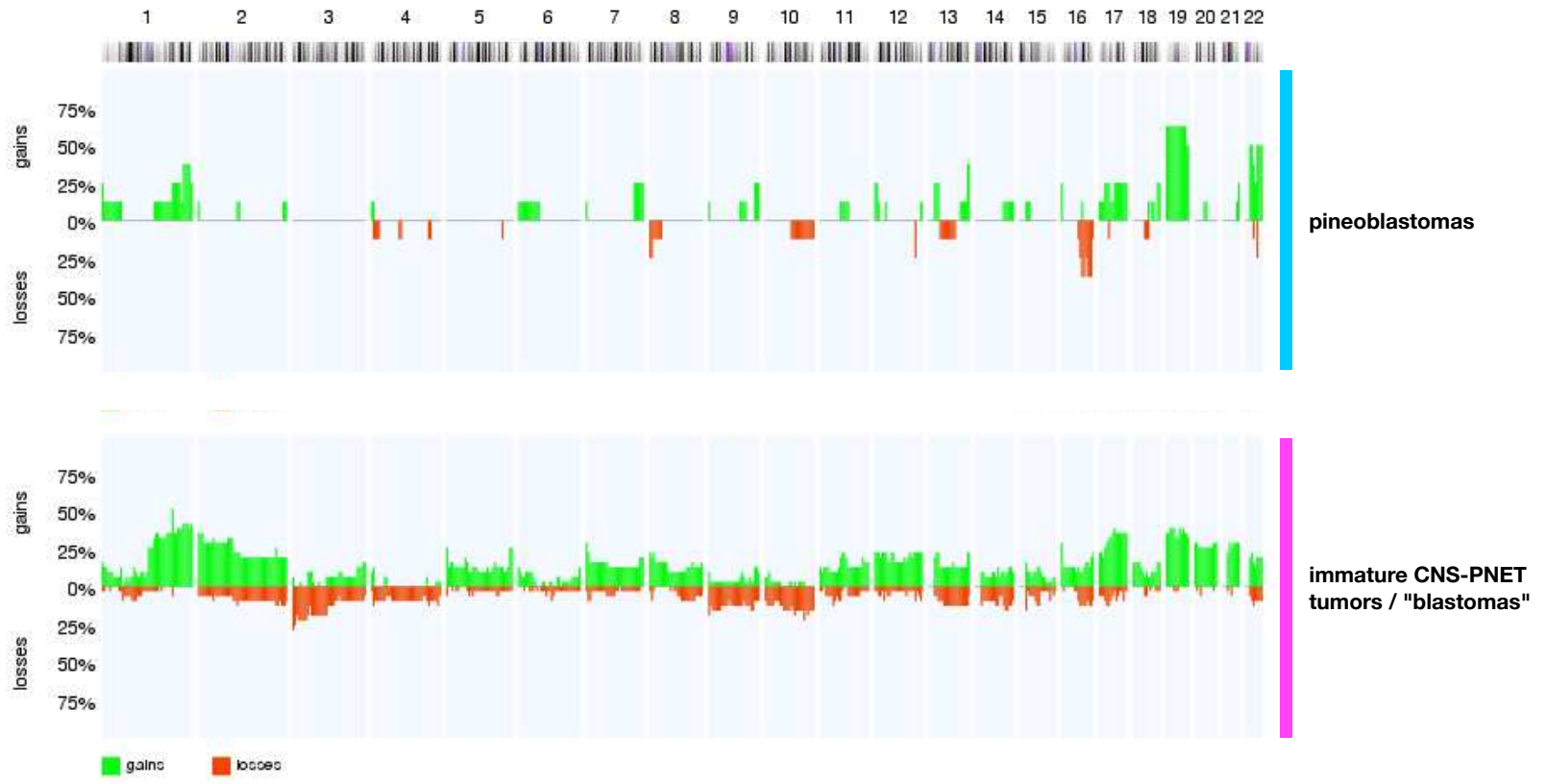




\section{von_Bueren_SupplementaryFigure 6}

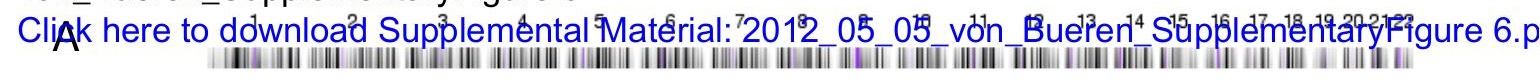
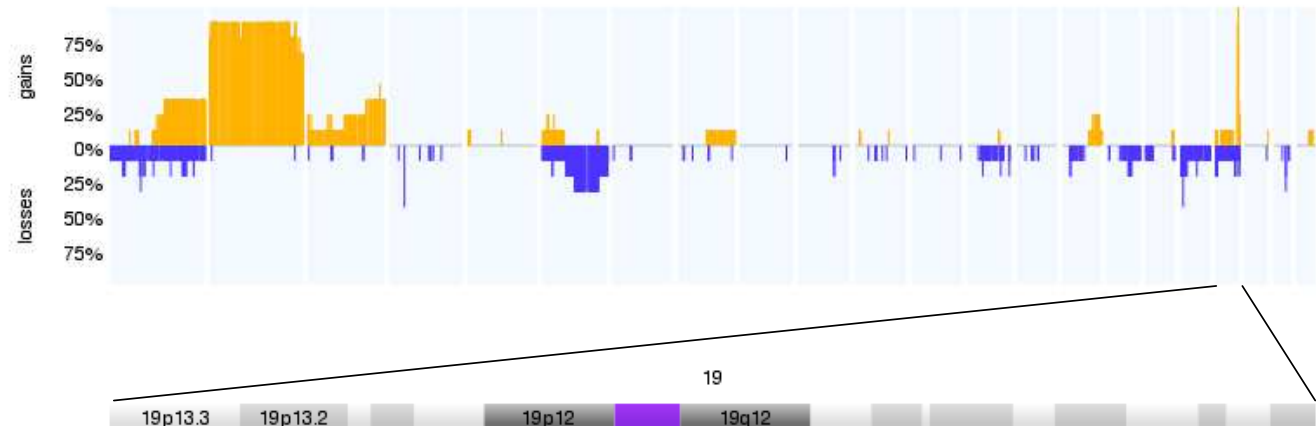

ต $50 \%$

$25 \%$

$25 \%$

$50 \%$

$75 \%$

B

GSM353436

chromosome (55000000-63000000)

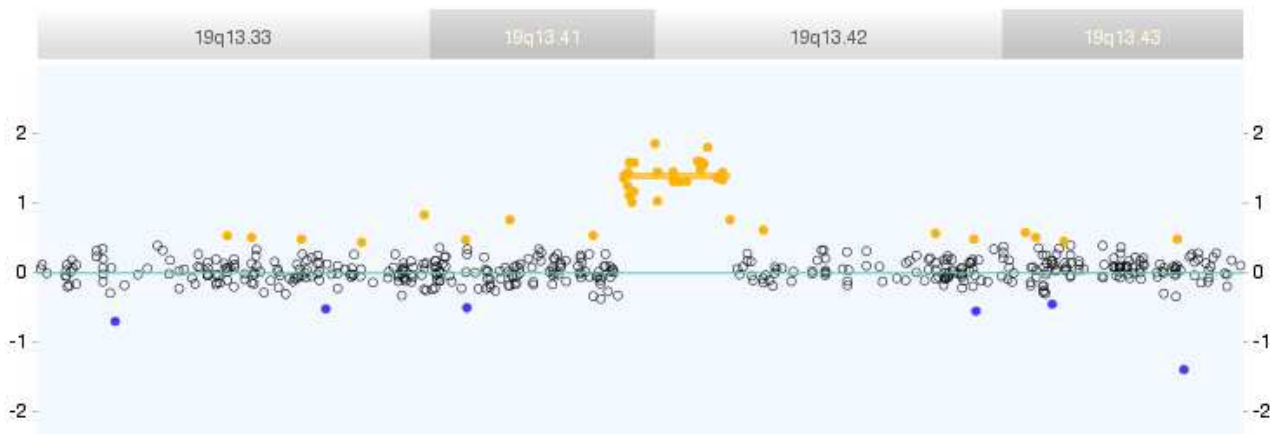

GSM353438

chromosome (55000000-63000000)

1991333

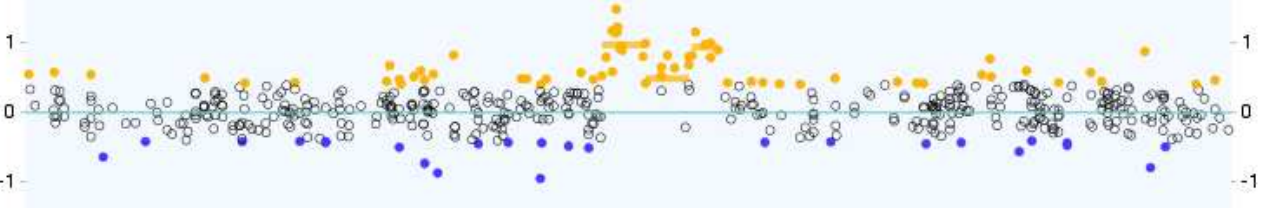

GSM353447

chromosome (55000000-63000000)

$19 q 13.33$

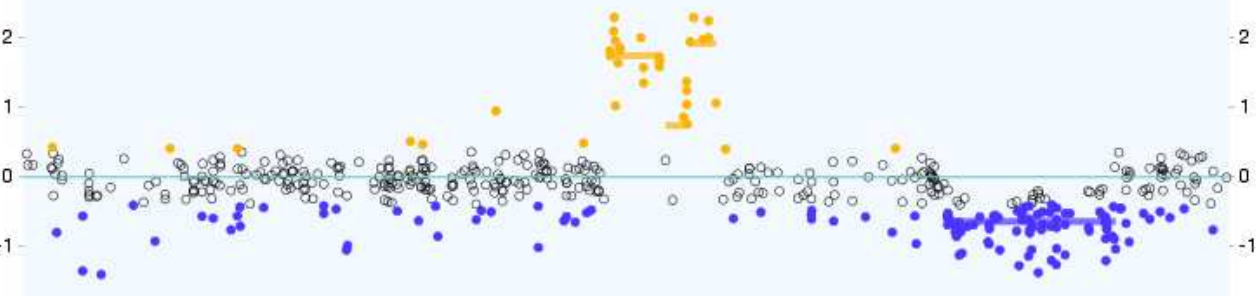

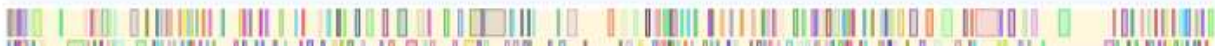

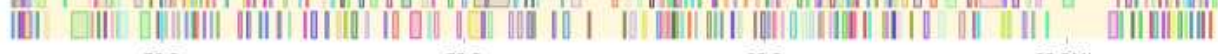
56.0 